\title{
Derivation of High Voltage-Gain Step-Up DC-DC Power Converters
}

\author{
Pekik Argo Dahono
}

\author{
School of Electrical Engineering and Informatics \\ Institute of Technology Bandung, INDONESIA
}

\begin{abstract}
This paper presents a new method to derive high voltage-gain step-up dc-dc power converters is presented in this paper. Four step-up dc-dc power converters are derived by a unique parallel-series combination of basic dc-dc power converters. The obtained high voltagegain power converters have better efficiency than the ones that can be obtained obtained by using a conventional dc-dc boost power converter. Interleaving the combined converters can be used to further reduce the input current and output voltage ripples. Simulation and measurement results are included to show the validity of the proposed concept of high voltage-gain step-up dc-dc power converters.
\end{abstract}

Keywords: DC-DC converter, voltage-gain, boost, buck-boost, Cuk

\section{Introduction}

Indonesia is an archipelago country with more than 17,000 islands that are distributed around the equator. Various renewable energy sources, such as solar (PV), wind, microhydro, fuel cell, and biomass have been used for powering remote and small islands in Indonesia. DC microgrid system is suitable for powering remote islands as many distributed energy sources and storages can be integrated easily.

In renewable power generation systems such as photovoltaic (PV), fuel cells, and wind power systems, a step-up dc-dc power converter is commonly used. The step-up dc-dc power converter is used as an interface between renewable power generation system and dc grid or dc bus. Moreover, such a high voltage-gain dc-dc power converter is also required in energy storage systems based on battery or ultracapacitor. In such applications, it is desirable to have a step-up dc-dc power converter with high voltage-gain, high efficiency, and low input current ripple. For these purposes, a conventional boost dc-dc power converter is the commonly used. By using a conventional dc-dc boost power converter, however, the maximum voltage gain or ratio is usually cannot be more than five. In dc microgrid applications, a voltage-gain more than ten is desirable.

Various step-up dc-dc power converters with high voltage-gain capability were proposed and reviewed in the literature [1]-[18]. A survey and comparison of various step-up dc-dc power converter topologies for renewable power applications are given in [1]-[6]. The nonisolated dc$\mathrm{dc}$ power converter is preferred because of efficiency and simplicity. At present, the most popular method to increase the converter voltage-gain is by cascading two or more dc-dc boost power converters. By cascading several dc-dc boost power converters, however, the efficiency is low because the power is processed twice or more. A high voltage-gain can also be obtained by using a center tap inductor or coupled inductors. By using this method, however, a very high voltage spike across the switching power devices is generated due to the leakage inductances. A step-up dc-dc power converter with continuous input current is desirable in order to have a low ripple input current. Interleaving technique is commonly used to reduce the input and output ripples.

This paper proposes a method to derive new high voltage-gain step-up dc-dc power converters. The new high voltage-gain step-up dc-dc power converters are derived by a unique combination of two basic dc-dc power converters. The two dc-dc power converters are connected in parallel on the input side but connected in series on the output side. The combined dc-dc power converters do not to be the same type. The carrier signals for both dc-dc power converters are identical but opposite in phase in order to reduce further the input current and 
output voltage ripples. It is shown that the current and voltage ripples can be reduced further by coupling the inductances in one magnetic core. Four new step-up dc-dc power converters are discussed in this paper. The converter output voltage expressions that take into account the voltage drops across the switching power devices and inductors are also derived. It is shown that the obtained step-up dc-dc power converters have lower conduction losses than the conventional dc-dc boost power converter. Several simulation and measurement results are included to show the validity of the proposed power converters. This paper is an extension of the paper by the author that has been presented in [19].

\section{New High Voltage-Gain Step-Up DC-DC Power Converters}

\section{A. Combination of $d c-d c$ boost power converters}

It has been mentioned in the previous section that a conventional dc-dc boost power converter is commonly used in renewable power generation systems. The basic scheme of conventional dc-dc boost power converter is shown in Figure 1. If both switching power devices (MOSFET and diode) are replaced by reverse conducting switches, the power flow can be bidirectional. Continuous input current is the main feature of conventional dc-dc boost power converters. Moreover, the dc output voltage is always higher than the dc input voltage. Low input current ripple content is very important in many applications such as photovoltaics, fuel cells, and batteries. Under continuous conduction mode, the voltage-gain of this boost dc-dc power converter is

$$
\frac{V_{L}}{E_{d}}=\frac{1}{1-k}
$$

where $k$ is the duty cycle of power transistor $Q$ with maximum value of unity. The scheme of dcdc boost power converter in Figure 1(a) can be redrawn as show in Figure 1(b) without changing the operation.

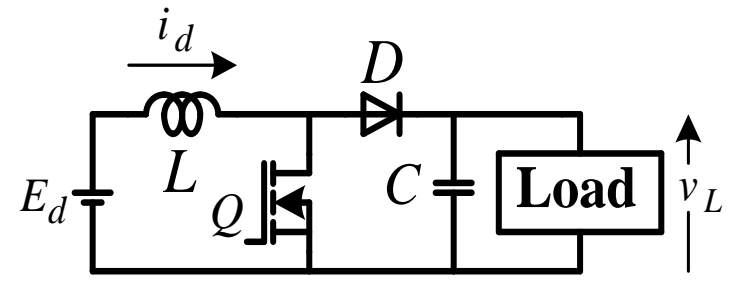

(a)

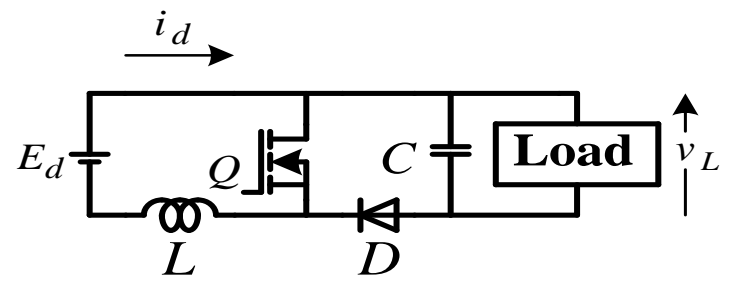

(b)

Figure 1. Conventional dc-dc boost power converter.

Eqn. (1) shows that the voltage-gain will become infinite when the duty cycle is close to unity. Practically, however, the voltage gain is limited because of voltage drops across the inductor and switching power devices. The maximum duty cycle is also limited by the minimum OFF-time of switching power device. Without a special measure, the maximum voltage-gain is usually about five. The input current ripple of dc-dc boost power converter is small because the inductor current is continuous. The input current ripple can be reduced further by interleaving several dcdc boost power converters.

A method to increase the achievable dc voltage-gain is using two or more dc-dc boost power converters connected in cascade. Because the electrical power is processed twice or more, 
however, the power efficiency can be very low. Thus, how to increase the voltage-gain without sacrificing the efficiency is still under interest of researchers.

Synthesis method that is used to combine two dc-dc power converter is similar to the one that is used in [17]. This synthesis method can be applied to any type of dc-dc power converters. How to combine two dc-dc boost power converters into one high voltage-gain dc-dc power converter is shown in Figure 2(a). The two converters are connected in parallel on the input side but connected in series on the output side. The scheme of this step-up dc-dc power converter is redrawn as shown in Figure 2(b) without changing the operation. Under continuous conduction mode of inductor currents, the dc voltage-gain is

$$
\frac{V_{L}}{E_{d}}=\frac{1+k}{1-k}
$$

Eqn. (2) shows that under the same duty cycle, the output voltage of boost derived converter in Figure 2 will be higher than the conventional dc-dc boost power converter in Figure 1. In the other words, for the same voltage-gain, the dc-dc boost derived power converter in Figure 2 needs a smaller duty cycle than the conventional dc-dc boost power converter.

The rated current of switching power devices of dc-dc power converter in Figure 2 is equal to the load current. On the other hand, the rated voltage of switching power device is

$$
V_{Q R}=V_{D R}=\frac{V_{L}}{1+k}
$$

Eqn. (3) shows that the rated voltage of switching devices is less than the rated load voltage. Thus, the processed power of each dc-dc power converter in Figure 2 is less than the total power.

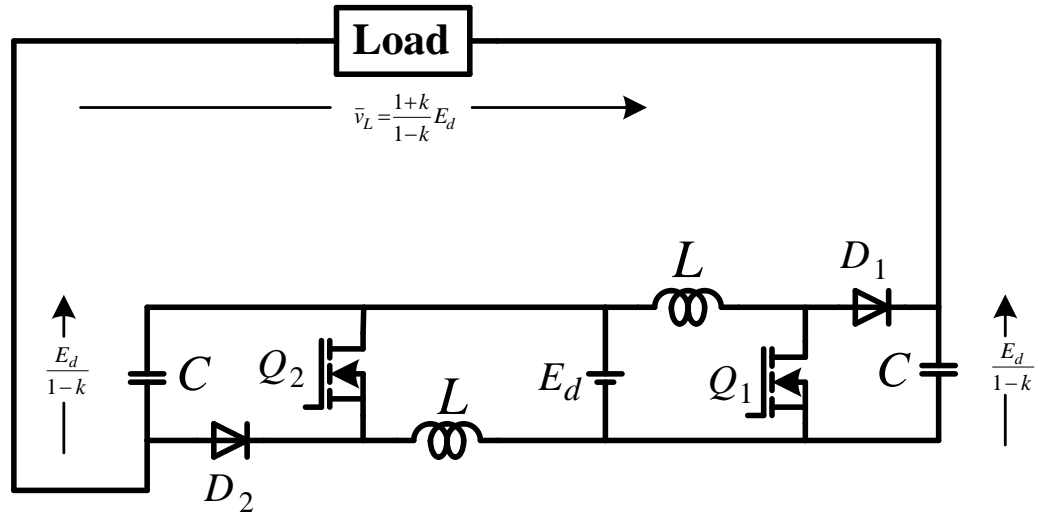

(a)

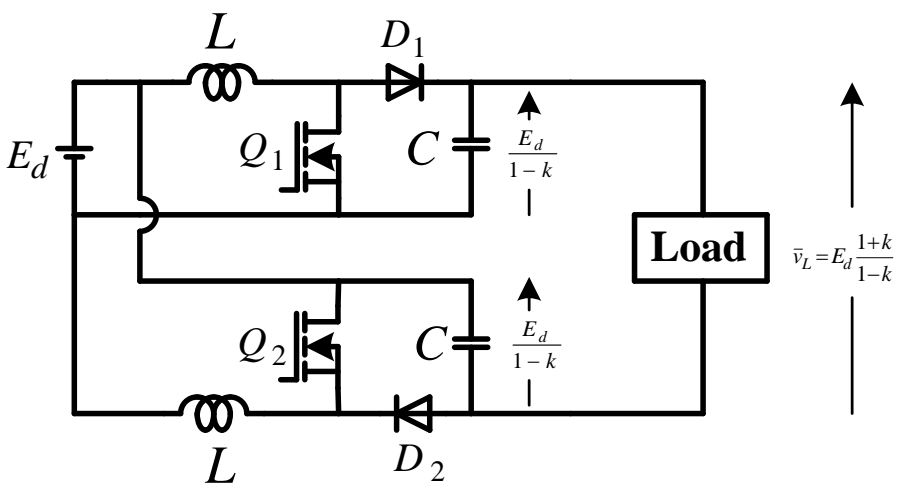

(b)

Figure 2. Combination of dc-dc boost power converters 
It should be noted that the voltage-gain in (2) is valid as long as the conduction mode of inductor current is continuous regardless the value of filter capacitors. Thus, the system is not sensitive to the difference of filter capacitors. This topology has been proposed in [18] but no detailed ripple analysis has been presented. This new step-up dc-dc power converter topology can also be extended to multiphase dc-dc boost power converters.

\section{B. Combination of buck-boost power converters}

Different to dc-dc boost power converter, the output voltage of dc-dc buck-boost power converter can be lower or higher than the input voltage. Both input and output currents of dc-dc buck-boost power converter are discontinuous. The output voltage polarity of dc-dc buck-boost power converter is reversed.

Two dc-dc buck-boost power converters can also be combined as shown in Figure 3. Once again, the inputs are connected in parallel but the outputs are connected in series. Under continuous conduction mode of inductor currents, the obtained voltage-gain is the same as given by (2). Similar to the dc-dc boost derived power converter, the voltage rating of switching devices in dc-dc buck-boost derived power converter is less than the output voltage.

The same as conventional dc-dc buck-boost power converter, the dc-dc power converter in Figure 3 has discontinuous input and output currents with the associated high ripple content. The large current ripple on the input may degrades the performance of PV modules, fuel cells, or batteries. The dc-dc buck-boost derived power converter, therefore, may not be useful as dc-dc boost derived power converter. By controlling the two dc-dc power converters as a two-phase dc-dc buck-boost power converter, the total input and output ripples can be reduced.

\section{Combination of boost and buck-boost power converters}

The dc-dc power converters that can be combined in parallel-series connection do not need to be the same converter type. If a boost and a buck-boost dc-dc power converters are combined, a new high voltage-gain dc-dc step-up power converter as shown in Figure 4 is obtained. Under continuous inductor current mode, the voltage-gain of this dc-dc power converter is the same as given by (2). Though the input current ripple of this dc-dc power converter is larger than the one in Figure 2, it is lower than the one in Figure 3. Similar to the dc-dc step-up power converters in Figs. 2 and 3, the two switching power devices in Figure 4 can also be operated as switching power devices in a two-phase dc-dc power converter to reduce further the ripple current content. It should be noted that the two dc-dc power converters in Figure 4 are not loaded equally. Thus, the rated voltages of switching power devices are not the same.

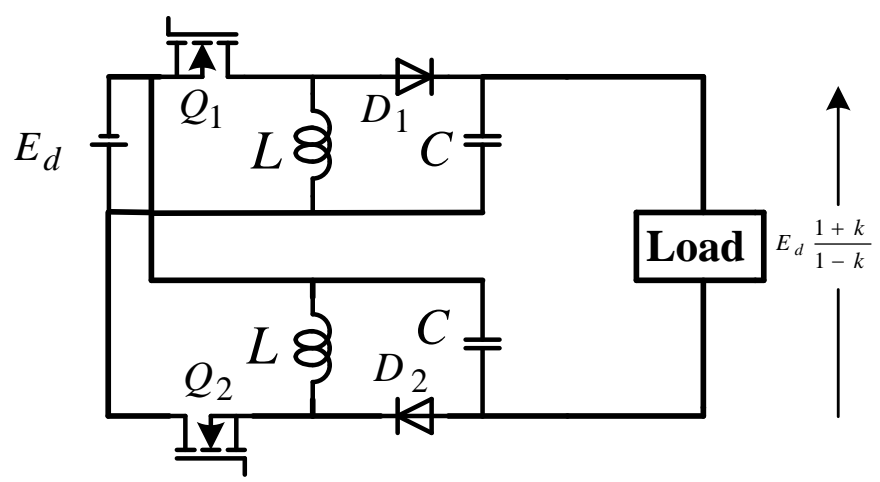

Figure 3. Combination of dc-dc buck-boost power converters. 


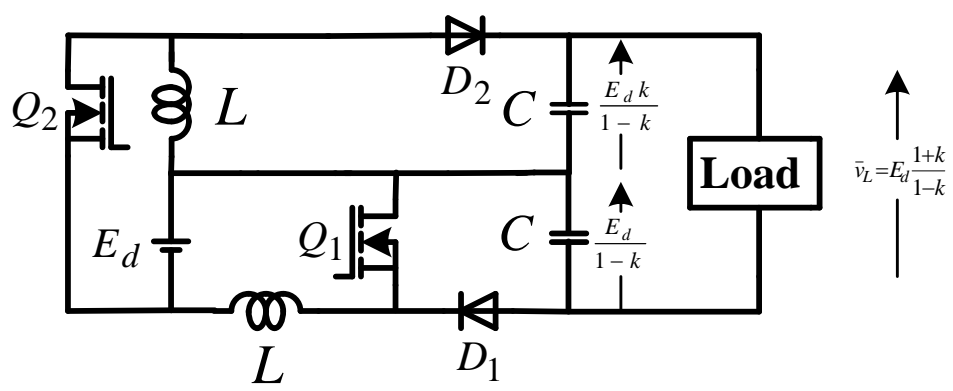

Figure 4. Combination of dc-dc boost and buck-boost power converters.

\section{Combination dc-dc Cuk power converters}

The main feature of Cuk converter is having continuous input and output currents and, therefore, low input and output current ripples. Similar as before, two dc-dc Cuk power converters can be connected in parallel and series as shown in Figure 5. This is a new high voltage-gain step-up dc-dc power converter with very low input and output current ripples. The voltage gain under continuous conduction mode is the same as in (2).

The current ripples of Cuk derived dc-dc power converter in Figure 5 can be reduced further by operating the dc-dc power converter similar to two-phase Cuk dc-dc power converter. Moreover, operation as two-phase Cuk dc-dc power converter will reduce also the capacitor ripple currents. The ripple currents can be reduced further by coupling the inductors in one magnetic core. Though the Cuk derived dc-dc power converter needs more components than the other dc-dc power converters, it will be shown later that the conduction losses are the lowest.

The concept that is used in this paper can be extended to other types of dc-dc power converters. Usefulness of the derived dc-dc power converters is determined by the application. No one dc-dc power converter is the best for any applications.

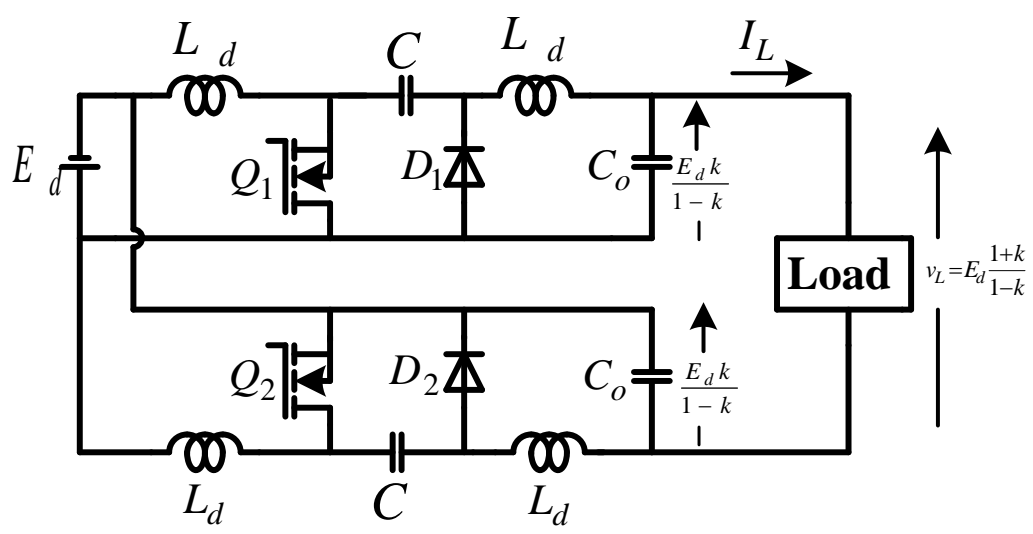

Figure 5. Combination of dc-dc Cuk power converters.

Figure 6 shows comparison of voltage-gains of the proposed and conventional step-up dc-dc power converters. This figure shows that for the same duty cycle, the proposed converters have higher voltage-gain than the conventional one. Thus, a higher voltage-gain can be obtained without operation at extreme duty cycles. 


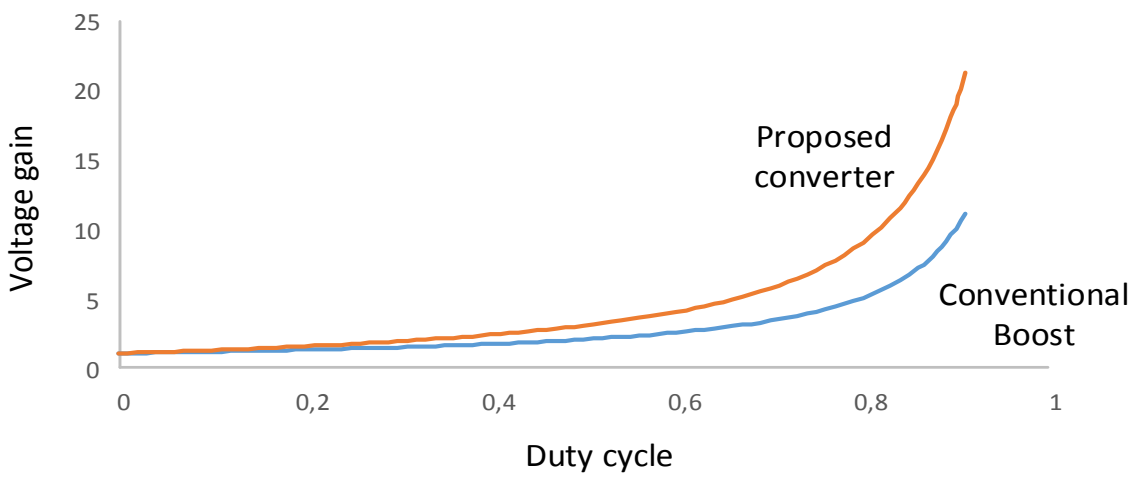

Figure 6. Ideal voltage-gain comparison.

\section{Analysis Of DC-DC Converter Voltage-Gain}

The expression of voltage gain as shown in (2) is obtained by assuming that all components are ideal components with no voltage drops. Practically, the inductors have finite series resistances and switching power devices have finite voltage drop during the conduction states. Due to these voltage drops, the converter output voltage cannot be increased infinitely. In this section, the effect of voltage drops is taken into account in voltage-gain analysis. For analysis in this section, it is assumed that the voltage drop across the switching power devices can be represented as a resistive drop plus a constant voltage drop. The inductors are assumed have a constant resistance. The filter capacitors are assumed as ideal capacitors with no parasitic components. To simplify the analysis, two switching devices in the dc-dc power converters are controlled by the same signals with equal duty cycles. The load is assumed as a constant current source. The analysis result is also useful to estimate the conduction losses.

For voltage-gain analysis, the dc-dc boost derived power converter is redrawn as shown in Figure 7. Under ON period when both power transistors Q1 and Q2 receive ON signals, both power diodes are in blocking state. Under ON period, the following state equation is obtained

$\left[\begin{array}{c}\frac{d i_{1}}{d t} \\ \frac{d i_{2}}{d t} \\ \frac{d v_{1}}{d t} \\ \frac{d v_{2}}{d t}\end{array}\right]=\left[\begin{array}{cccc}-\frac{R_{L}+R_{Q}}{L} & 0 & 0 & 0 \\ 0 & -\frac{R_{L}+R_{Q}}{L} & 0 & 0 \\ 0 & 0 & 0 & 0 \\ 0 & 0 & 0 & 0\end{array}\right]\left[\begin{array}{c}i_{1} \\ i_{2} \\ v_{1} \\ v_{2}\end{array}\right]+\left[\begin{array}{c}\frac{E_{d}-V_{Q}}{L} \\ \frac{E_{d}-V_{Q}}{L} \\ -\frac{I_{L}}{C} \\ -\frac{I_{L}}{C}\end{array}\right]$

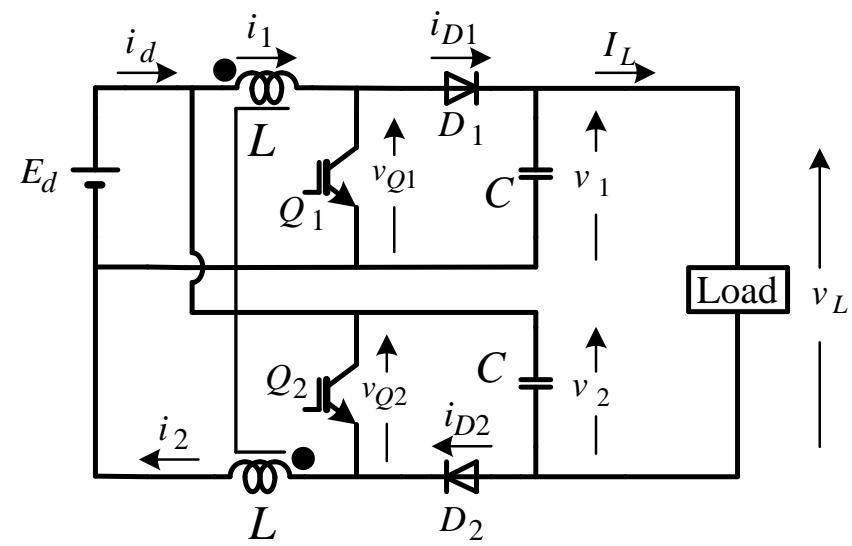

Figure 7. Combination of dc-dc boost power converters. 
where $R_{L}$ is the resistance of boost inductors, $R_{Q}$ is the resistance of power transistors during conduction mode, and $V_{Q}$ is the constant voltage drop across the power transistors.

Under OFF period when both power transistors receive OFF signals, both power diodes are in conduction mode. The state equation during OFF period is

$$
\left[\begin{array}{c}
\frac{d i_{1}}{d t} \\
\frac{d i_{2}}{d t} \\
\frac{d v_{1}}{d t} \\
\frac{d v_{2}}{d t}
\end{array}\right]=\left[\begin{array}{cccc}
-\frac{R_{L}+R_{D}}{L} & 0 & -\frac{1}{L} & 0 \\
0 & -\frac{R_{L}+R_{D}}{L} & 0 & -\frac{1}{L} \\
\frac{1}{C} & 0 & 0 & 0 \\
0 & \frac{1}{C} & 0 & 0
\end{array}\right]\left[\begin{array}{c}
i_{1} \\
i_{2} \\
v_{1} \\
v_{2}
\end{array}\right]+\left[\begin{array}{c}
\frac{E_{d}-V_{D}}{L} \\
\frac{E_{d}-V_{D}}{L} \\
-\frac{I_{L}}{C} \\
-\frac{I_{L}}{C}
\end{array}\right]
$$

where $R_{D}$ is the resistance and $V_{D}$ is the constant voltage drop of power diodes during conduction mode.

Applying the state-space averaging to eqns. (4) and (5) over one switching period, the following state equation is obtained

$$
\left[\begin{array}{c}
\frac{d \bar{i}_{1}}{d t} \\
\frac{d \bar{i}_{2}}{d t} \\
\frac{d \bar{v}_{1}}{d t} \\
\frac{d \bar{v}_{2}}{d t}
\end{array}\right]=\left[\begin{array}{cccc}
-\frac{R_{L}+R_{Q} k+R_{D}(1-k)}{L} & 0 & -\frac{1-k}{L} & 0 \\
0 & -\frac{R_{L}+R_{Q} k+R_{D}(1-k)}{L} & 0 & -\frac{1-k}{L} \\
\frac{1-k}{C} & 0 & 0 & 0 \\
0 & \frac{1-k}{C} & 0 & 0
\end{array}\right]\left[\begin{array}{c}
\bar{i}_{1} \\
\bar{i}_{2} \\
\bar{v}_{1} \\
\bar{v}_{2}
\end{array}\right]+\left[\begin{array}{c}
\frac{E_{d}-V_{Q} k-V_{D}(1-k)}{L} \\
\frac{E_{d}-V_{Q} k-V_{D}(1-k)}{L} \\
-\frac{I_{L}}{C} \\
-\frac{I_{L}}{C}
\end{array}\right]
$$

In (6), bar over the variables denotes the average or dc component. Under steady-state condition, the left hand side of (6) is zero,

$$
0=\left[\begin{array}{cccc}
-\frac{R_{L}+R_{Q} k+R_{D}(1-k)}{L} & 0 & -\frac{1-k}{L} & 0 \\
0 & -\frac{R_{L}+R_{Q} k+R_{D}(1-k)}{L} & 0 & -\frac{1-k}{L} \\
\frac{1-k}{C} & 0 & 0 & 0 \\
0 & \frac{1-k}{C} & 0 & 0
\end{array}\right]\left[\begin{array}{c}
\bar{i}_{1} \\
\bar{i}_{2} \\
\bar{v}_{1} \\
\bar{v}_{2}
\end{array}\right]+\left[\begin{array}{c}
\frac{E_{d}-V_{Q} k-V_{D}(1-k)}{L} \\
\frac{E_{d}-V_{Q} k-V_{D}(1-k)}{L} \\
-\frac{I_{L}}{C} \\
-\frac{I_{L}}{C}
\end{array}\right] \text { (7) }
$$

Based on (7), the output voltage of dc-dc boost derived power converter is

$$
\bar{v}_{L}=E_{d} \frac{1+k}{1-k}-2 \frac{V_{Q^{k}+V_{D}(1-k)}}{1-k}-2 \frac{R_{L}+R_{Q^{k}+R_{D}(1-k)}}{(1-k)^{2}} I_{L}
$$

The output voltage expressions of buck-boost derived power converter in Figure 3 and boost and buck-boost derived power converter in Figure 4 can be obtained in the same way and the results are the same as given by (8). The output voltage expression of dc-dc Cuk derived power converter can be obtained similarly and the result is

$$
\bar{v}_{L}=E_{d} \frac{1+k}{1-k}-2 \frac{V_{Q} k+V_{D}(1-k)}{1-k}-2 \frac{R_{L}\left(1-2 k+2 k^{2}\right)+R_{Q} k+R_{D}(1-k)}{(1-k)^{2}} I_{L}
$$

Eqns. (8) and (9) show that the voltage drops across the switching power devices and inductors are infinite when the duty cycle is close to unity. Thus, the output voltage of the dcdc power converters cannot be infinite.

The output power of the converter is

$$
P_{L}=\bar{v}_{L} I_{L}
$$


Substituting (8) into (10), the following is obtained

$$
P_{L}=E_{d} \frac{1+k}{1-k} I_{L}-2 \frac{V_{Q} k+V_{D}(1-k)}{1-k} I_{L}-2 \frac{R_{L}+R_{Q^{k}+R_{D}(1-k)}}{(1-k)^{2}} I_{L}^{2}
$$

The input power is

$$
P_{d}=E_{d} \bar{i}_{d}=E_{d} \frac{1+k}{1-k} I_{L}
$$

The losses are

$$
P_{\text {loss }}=P_{d}-P_{L}=2 \frac{V_{Q^{k}+V_{D}(1-k)}}{1-k} I_{L}+2 \frac{R_{L}+R_{Q^{k+R}}(1-k)}{(1-k)^{2}} I_{L}^{2}
$$

If the losses are just conduction losses, therefore, the voltage drops across the switching power devices and inductors can be used to estimate the dc-dc power converter losses.

The output voltage of conventional dc-dc boost power converter can be obtained similarly and the result is

$$
\bar{v}_{L}=\frac{E_{d}}{1-k}-\frac{V_{Q} k+V_{D}(1-k)}{1-k}-\frac{R_{L}+R_{Q} k+R_{D}(1-k)}{(1-k)^{2}} I_{L}
$$

Under the same output voltage-gain, six for example, the proposed dc-dc power converters needs a duty cycle of $5 / 7$. On the other hand a conventional dc-dc boost power converter needs a duty cycle of 5/6. By using eqns. (8)-(9) and (14), the voltage drop across the inductors of conventional dc-dc boost power converter is 72/49 times the proposed power converters. All proposed step-up dc-dc power converters have smaller conduction losses than the conventional $\mathrm{dc}-\mathrm{dc}$ boost power converter. Though the dc-dc Cuk derived power converter needs more components than the others, eqn. (9) shows that the conduction losses of dc-dc Cuk derived power converter are the lowest.

Figure 8 shows comparison of voltage-gains among conventional boost, boost-derived, and Cuk derived dc-dc converters when the inductor resistances are taken into account. The inductor resistances are assumed equal to $0.5 \mathrm{ohm}$. The load resistance is assumed as $100 \mathrm{ohm}$. The switching devices were assumed as ideal switching devices. This figure shows that the Cuk derived dc-dc power converter has the highest achievable voltage-gain. Figure 10 also shows that the voltage drop across the inductors has made the achievable voltage-gain is limited. That means the Cuk derived converter has the lowest losses.

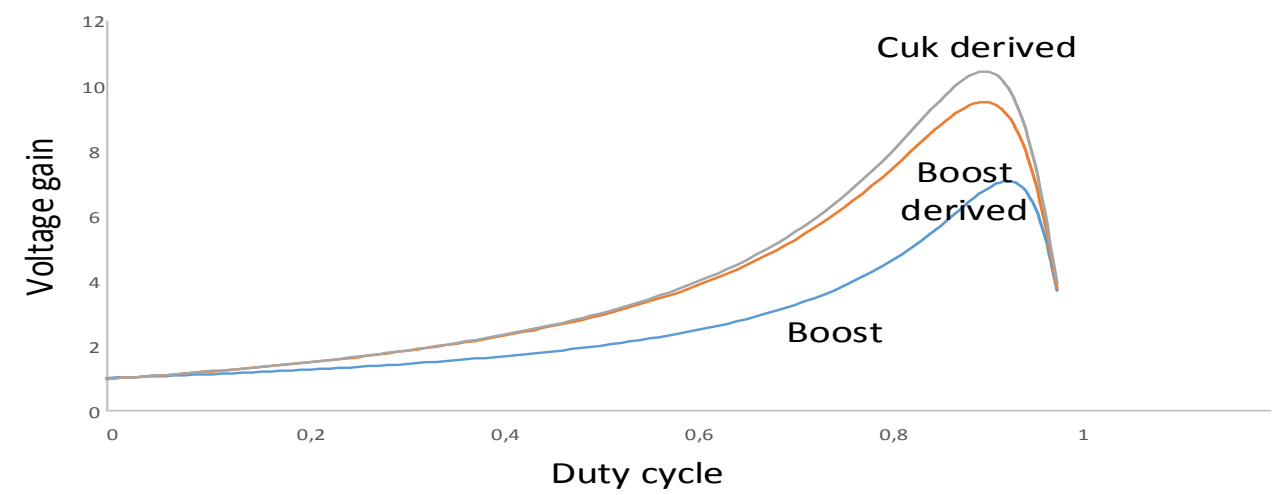

Figure 8. Voltage-gain comparison.

\section{Analysis of Current and Voltage Ripples}

Analysis of current and voltage ripples of dc-dc boost derived power converter is detailed here. Ripple analysis results are important in determining the required filter inductor and capacitor. In this ripple analysis, it is assumed that the dc source is a constant dc voltage source with no ripple content. The load for this dc-dc power converter is assumed as an inductive load 
so that it can be represented as a current source with no ripple. The switching power devices are assumed as ideal switching power devices.

\section{A. Analysis of current ripple}

For ripple analysis purpose, the two inductors of power converter in Figure 7 are assumed equal to $L$. These two inductances are coupled in one magnetic core to reduce further the current ripple. The two capacitors of power converter are also assumed equal to $C$. The switching signals for power transistors $Q_{1}$ and $Q_{2}$ are equal but shifted $180^{\circ}$ to reduce further the current and voltage ripples. By using this switching signals, the ripple behavior of this dc-dc power converter will be similar to two-phase dc-dc boost power converter.

The inductor currents of dc-dc power converter circuit in Figure 7 can be obtained as

$$
\left[\begin{array}{c}
\frac{d i_{1}}{d t} \\
\frac{d i_{2}}{d t}
\end{array}\right]=\left[\begin{array}{cc}
\frac{L}{\Delta} & -\frac{M}{\Delta} \\
-\frac{M}{\Delta} & \frac{L}{\Delta}
\end{array}\right]\left[\begin{array}{c}
E_{d}-v_{Q 1} \\
E_{d}-v_{Q 2}
\end{array}\right]
$$

In eqn. (15), $v_{Q 1}$ and $v_{Q 2}$ are voltages across power transistors $Q_{1}$ and $Q_{2}$, respectively. The coupled inductor has a mutual inductance of $M$ and $\Delta=L^{2}-M$. The currents and voltages can be separated into the average and ripple components, that is,

$$
\begin{aligned}
& i_{1}=\bar{i}_{1}+\tilde{i}_{1} \\
& i_{2}=\bar{i}_{2}+\tilde{i}_{2} \\
& v_{Q 1}=\bar{v}_{Q 1}+\tilde{v}_{Q 1} \\
& v_{Q 2}=\bar{v}_{Q 2}+\tilde{v}_{Q 2}
\end{aligned}
$$

In eqns. (16)-(19), bar denotes average and tilde denotes ripple components, respectively. If eqns. (16)-(19) are substituted into (15), the following current ripple expression can be obtained:

$$
\left[\begin{array}{l}
\frac{d \tilde{i}_{1}}{d t} \\
\frac{d \tilde{i_{2}}}{d t}
\end{array}\right]=\left[\begin{array}{cc}
\frac{L}{\Delta} & -\frac{M}{\Delta} \\
-\frac{M}{\Delta} & \frac{L}{\Delta}
\end{array}\right]\left[\begin{array}{l}
-\tilde{v}_{Q 1} \\
-\tilde{v}_{Q 2}
\end{array}\right]
$$

or

$$
\begin{aligned}
& \frac{d \tilde{i}_{1}}{d t}=-\frac{L}{\Delta} \tilde{v}_{Q 1}+\frac{M}{\Delta} \tilde{v}_{Q 2} \\
& \frac{d \tilde{i_{2}}}{d t}=\frac{M}{\Delta} \tilde{v}_{Q 1}-\frac{L}{\Delta} \tilde{v}_{Q 1}
\end{aligned}
$$

Using eqns. (21)-(22), the boost inductor current ripple expressions can be obtained as follows:

$$
\begin{aligned}
& \tilde{\dot{1}}=-\frac{L}{\Delta} \int_{t_{O}}^{t_{o}+t} \tilde{v}_{Q 1} d t+\frac{M}{\Delta} \int_{t_{O}}^{t} \tilde{v}_{Q 2}+G_{1} \\
& \tilde{i}_{2}=-\frac{L}{\Delta} \int_{t_{O}}^{t_{o}+t} \tilde{v}_{Q 2} d t+\frac{M}{\Delta} \int_{t_{O}}^{t} \tilde{v}_{Q 1}+G_{2}
\end{aligned}
$$

where $G_{1}$ and $G_{2}$ are constants of integration.

As the load current is assumed as an ideal dc load current, the ripple of current flowing from the source is

$$
\tilde{i}_{d}=\tilde{i}_{1}+\tilde{i}_{2}
$$

Using eqns. (23)-(25), the dc source current ripple is

$$
\tilde{i}_{d}=-\frac{1}{L+M} \int_{t_{o}}^{t_{o}+t}\left(\tilde{v}_{Q 1}+\tilde{v}_{Q 2}\right) d t+G_{3}
$$

where $G_{3}$ is a constant of integration. 


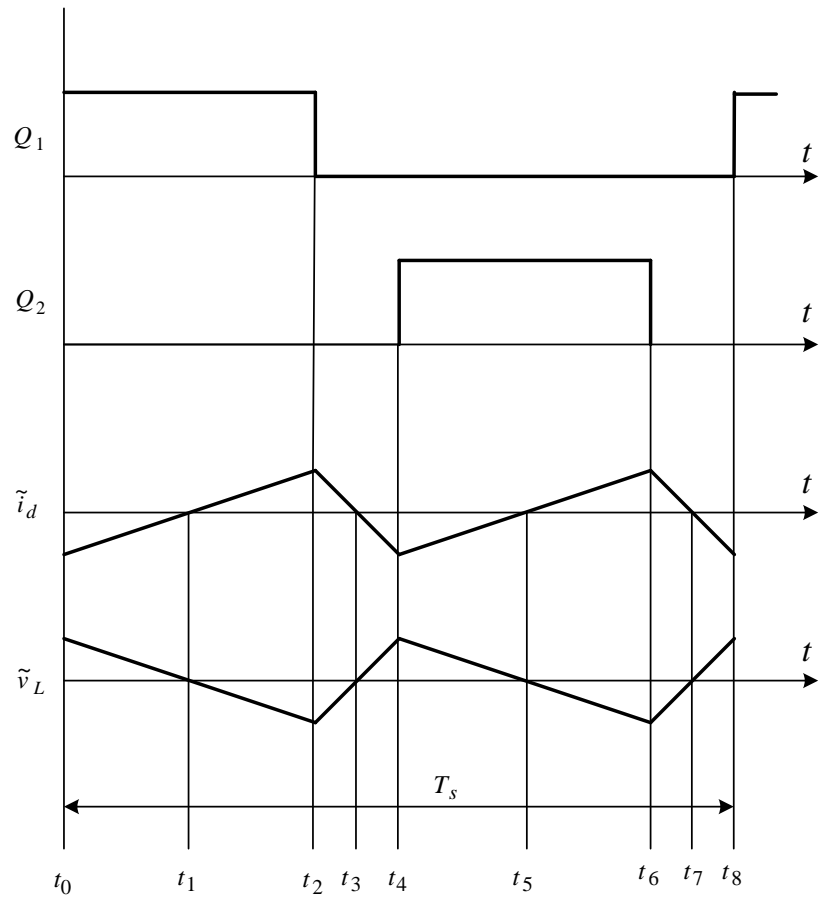

Figure 9. DC-DC power converter waveforms over one switching period.

Figure 9 shows dc-dc power converter waveforms when the duty cycle is less than half. The voltage across the power transistor is zero when an ON signal is received. If a power transistor receives an OFF signal the voltage across the power transistor is equal to the corresponding output voltage. Based on Figure 9, the ripple components of $v_{Q 1}$ and $v_{Q^{2}}$ over one switching period can be written as

$$
\begin{gathered}
\tilde{v}_{Q 1}=\left\{\begin{array}{ccc}
-E_{d} & \text { for } & t_{o} \leq t \leq t_{O}+k T_{S} \\
\tilde{v}_{1}-E_{d} & \text { for } & t_{o}+k T_{S} \leq t \leq t_{O}+T_{S}
\end{array}\right. \\
\tilde{v}_{Q 2}=\left\{\begin{array}{ccc}
\bar{v}_{2}-E_{d} & \text { for } & t_{o} \leq t \leq t_{O}+\frac{T_{S}}{2} \\
-E_{d} & \text { for } & t_{o}+\frac{T_{S}}{2} \leq t \leq t_{o}+\frac{T_{S}}{2}+k T_{S} \\
\bar{v}_{2}-E_{d} & \text { for } & t_{o}+\frac{T_{S}}{2}+k T_{S} \leq t \leq t_{o}+T_{S}
\end{array}\right.
\end{gathered}
$$

where $T_{s}$ is switching period.

The average or dc values of $v_{1}$ and $v_{2}$ are equal to

$$
\bar{v}_{1}=\bar{v}_{2}=\frac{E_{d}}{1-k}
$$

Using eqns. (27)-(29), the ripple component of power transistor voltages are:

$$
\tilde{v}_{Q 1}=\left\{\begin{array}{lll}
-E_{d} & \text { for } & t_{o} \leq t \leq t_{o}+k T_{S} \\
\frac{E_{d} k}{1-k} & \text { for } & t_{o}+k T_{S} \leq t \leq t_{O}+T_{S}
\end{array}\right.
$$




$$
\tilde{v}_{Q 2}=\left\{\begin{array}{llc}
\frac{E_{d} k}{1-k} & \text { for } & t_{o} \leq t \leq t_{o}+\frac{T_{S}}{2} \\
-E_{d} & \text { for } & t_{o}+\frac{T_{S}}{2} \leq t \leq t_{o}+\frac{T_{S}}{2}+k T_{S} \\
\frac{E_{d} k}{1-k} & \text { for } & t_{o}+\frac{T_{S}}{2}+k T_{S} \leq t \leq t_{O}+T_{S}
\end{array}\right.
$$

Using eqns. (26) and (30)-(31), the expression of source current ripple over one switching period is

$$
\tilde{i}_{d}=\frac{E_{d}}{(L+M)}\left\{\begin{array}{ccc}
-\frac{(1-2 k) k T_{S}}{2}+(1-2 k)\left(t-t_{o}\right) & \text { for } & t_{o} \leq t \leq t_{2} \\
\frac{(1-2 k) k T_{S}}{2}-2 k\left(t-t_{2}\right) & \text { for } & t_{2} \leq t \leq t_{4} \\
-\frac{(1-2 k) k T_{S}}{2}+(1-2 k)\left(t-t_{4}\right) & \text { for } & t_{4} \leq t \leq t_{6} \\
\frac{(1-2 k) k T_{S}}{2}-2 k\left(t-t_{6}\right) & \text { for } & t_{6} \leq t \leq t_{8}
\end{array}\right.
$$

The rms value of source current ripple over one switching period is

$$
\tilde{I}_{d}=\left[\frac{1}{T_{S}} \int_{t_{o}}^{t_{o}+T_{S}} \tilde{i}_{d}^{2} d t\right]^{1 / 2}
$$

Substituting (32) into (33) and performing the integration, the following is obtained

$$
\tilde{I}_{d}=\frac{E_{d}}{f_{S}(L+M)} \frac{k(1-2 k)}{2 \sqrt{3}(1-k)}
$$

where $f_{s}$ is the switching frequency. When the duty cycle is equal to half, eqn. (34) shows that the input current ripple is zero. This equation also shows that the input current ripple can be reduced further by coupling both inductances in one magnetic core.

The source current ripple expression for duty cycle more than half can be obtained similarly and the results is

$$
\tilde{I}_{d}=\frac{E_{d}}{f_{S}(L+M)} \frac{(2 k-1)}{2 \sqrt{3}}
$$

This current ripple expression is useful to determine the required inductors.

\section{B. Analysis of output voltage ripple}

Using the dc-dc power converter circuit in Figure 6, the following capacitor currents can be obtained

$$
\begin{aligned}
& i_{C 1}=i_{D 1}-I_{L} \\
& i_{C 2}=i_{D 2}-I_{L}
\end{aligned}
$$

Similar to the previous analysis, the capacitor currents can be separated into the average and ripple components,

$$
\begin{aligned}
& i_{C 1}=\bar{i}_{C 1}+\tilde{i}_{C 1} \\
& i_{C 2}=\bar{i}_{C 2}+\tilde{i}_{C 2} \\
& i_{D 1}=\bar{i}_{D 1}+\tilde{i}_{D 1} \\
& i_{D 2}=\bar{i}_{D 2}+\tilde{i}_{D 2}
\end{aligned}
$$

Once again, bar and tilde over the variables denote the average and ripple components, respectively. If eqns. (38)-(41) are substituted into (36)-(37), the followings capacitor current ripples can be obtained

$$
\begin{aligned}
& \tilde{i}_{C 1}=\tilde{i}_{D 1} \\
& \tilde{i}_{C 2}=\tilde{i}_{D 2}
\end{aligned}
$$


As the load current is assumed to be a pure dc current, the capacitor current ripples are the same as the diode current ripples. Thus,

$$
\begin{aligned}
& \tilde{i}_{C 1} \approx \tilde{i}_{D 1}=i_{D 1}-\bar{i}_{D 1} \\
& \tilde{i}_{C 2} \approx \tilde{i}_{D 2}=i_{D 2}-\bar{i}_{D 2}
\end{aligned}
$$

Based on the above capacitor ripple currents, the capacitor voltage ripples are

$$
\begin{aligned}
& \tilde{v}_{C 1}=\int \tilde{i}_{C 1} d t=\int\left(i_{D 1}-\bar{i}_{D 1}\right) d t \\
& \tilde{v}_{C 2}=\int \tilde{i}_{C 2} d t=\int\left(i_{D 2}-\bar{i}_{D 2}\right) d t
\end{aligned}
$$

The average or dc current through the converter inductors are

$$
\bar{i}_{1}=\bar{i}_{2}=\frac{I_{L}}{1-k}
$$

The average or dc current through the power diodes are

$$
\bar{i}_{D 1}=\bar{i}_{D 2}=I_{L}
$$

Over one switching period, the power diode currents are

$$
\begin{gathered}
i_{D 1}=\left\{\begin{array}{llc}
0 & \text { for } & t_{o} \leq t \leq t_{O}+k T_{S} \\
\bar{i}_{1} & \text { for } & t_{O}+k T_{S} \leq t \leq t+T_{S}
\end{array}\right. \\
i_{D 2}=\left\{\begin{array}{lcc}
\bar{i}_{2} & \text { for } & t_{O} \leq t \leq t_{O}+\frac{T_{S}}{2} \\
0 & \text { for } & t_{O}+\frac{T_{S}}{2} \leq t \leq t_{O}+\frac{T_{S}}{2}+k T_{S} \\
\bar{i}_{2} & \text { for } & t_{O}+\frac{T_{S}}{2}+k T_{S} \leq t \leq t_{O}+T_{S}
\end{array}\right.
\end{gathered}
$$

Using (48)-(51), the expressions of power diode current ripples are

$$
\begin{gathered}
\tilde{i}_{D 1}=\left\{\begin{array}{ccc}
-\frac{I_{L}}{1-k} & \text { for } & t_{O} \leq t \leq t_{O}+k T_{S} \\
\frac{k I_{L}}{1-k} & \text { for } & t_{O}+k T_{S} \leq t \leq t_{O}+T_{S}
\end{array}\right. \\
\tilde{i}_{D 2}=\left\{\begin{array}{ccc}
\frac{k I_{L}}{1-k} & \text { for } & t_{O} \leq t \leq t_{O}+\frac{T_{S}}{2} \\
-\frac{I_{L}}{1-k} & \text { for } & t_{o}+\frac{T_{S}}{2} \leq t \leq t_{O}+\frac{T_{S}}{2}+k T_{S} \\
\frac{k I_{L}}{1-k} & \text { for } & t_{O}+\frac{T_{S}}{2}+k T_{S} \leq t \leq t_{O}+T_{S}
\end{array}\right.
\end{gathered}
$$

The integration of the current ripple can be used to determine the output voltage ripple as follow

$$
\tilde{v}_{L}=\tilde{v}_{C 1}+\tilde{v}_{C 2}=\frac{1}{C} \int\left(\tilde{i}_{D 1}+\tilde{i}_{D 2}\right) d t
$$

If eqns. (52)-(53) are substituted into (54) and performing the integration, we can obtain the following output voltage ripple expression:

$$
\tilde{v}_{L}=\frac{I_{L}}{C(1-k)}\left\{\begin{array}{ccc}
\frac{(1-2 k) k T_{S}}{2}-(1-2 k)\left(t-t_{o}\right) & \text { for } & t_{o} \leq t \leq t_{O}+k T_{S} \\
-\frac{(1-2 k) k T_{S}}{2}+2 k\left(t-t_{2}\right) & \text { for } & t_{o}+k T_{S} \leq t \leq t_{O}+\frac{T_{S}}{2} \\
\frac{(1-2 k) k T_{S}}{2}-(1-2 k)\left(t-t_{4}\right) & \text { for } & t_{o}+\frac{T_{S}}{2} \leq t \leq t_{O}+\frac{T_{S}}{2}+k T_{S} \\
-\frac{(1-2 k) k T_{S}}{2}+2 k\left(t-t_{6}\right) & \text { for } & t_{o}+\frac{T_{S}}{2}+k T_{S} \leq t \leq t_{o}+T_{S}
\end{array}\right.
$$

Using eqn. (55), the rms value of the converter output voltage ripple can be obtained as follow

$$
\tilde{V}_{L}=\frac{I_{L}}{C f_{S}} \frac{k(1-2 k)}{2 \sqrt{3}(1-k)}
$$

The output voltage ripple for duty cycles more than half can be obtained similarly and the result is 


$$
\tilde{V}_{L}=\frac{I_{L}}{C f_{S}} \frac{(2 k-1)}{2 \sqrt{3}}
$$

Similar to the source current ripple, the output voltage ripple is zero when the duty cycle is half. Thus, the input and output ripples of the boost derived dc-dc power converter are similar to two-phase dc-dc boost power converter.

The input and output ripples of new dc-dc power converters in Figs. 3, 4, and 5 can be determined similarly. It can be shown that the Cuk derived power converter has the lowest ripples.

\section{Simulation and Measurement Results}

A. Simulation results for boost derived $d c-d c$ power converter

The new dc-dc boost derived power converter as shown in Figure 6 is simulated. The inductances used in the simulation are $1.5 \mathrm{mH}$ with coupling coefficient $M$ equal to 0.7 . The filter capacitances of the dc-dc power converter are equal to $200 \mu \mathrm{F}$. The switching or carrier frequency was fixed at $10 \mathrm{kHz}$. The load is assumed as a constant resistive load of $60 \mathrm{ohm}$. The dc input voltage was maintained constant at $36 \mathrm{Vdc}$.

The boost derived dc-dc power converter system is simulated under open loop condition. Figs. 10 and 11 show simulation results when the duty cycles are half and 0.75 , respectively. These simulation results show that the dc-dc power converter waveforms are very close to the expected ones. When the dc-dc power converter is operated under duty cycle of half, the input current and output voltage ripples are zero. The frequency of source current ripple and output voltage ripple are twice the switching frequency.

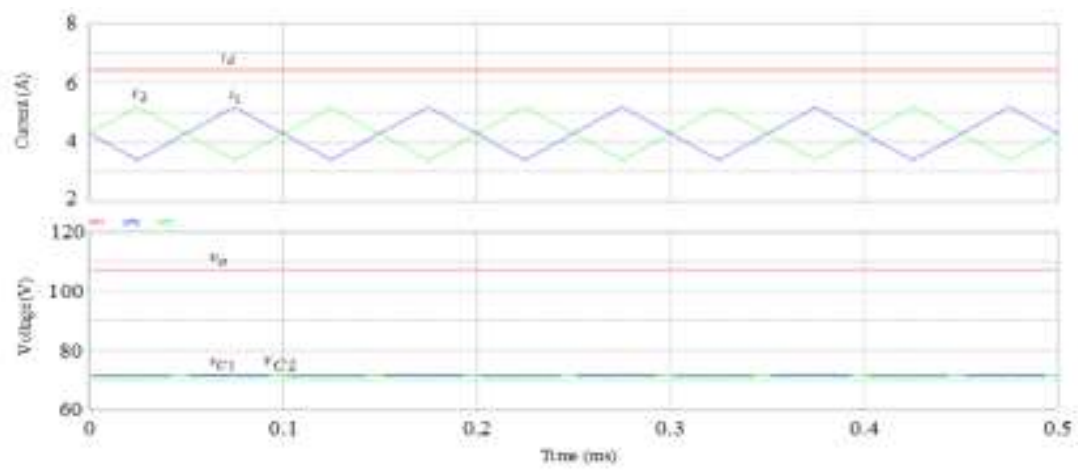

Figure 10. Simulation result of boost derived converter when duty cycle is half.
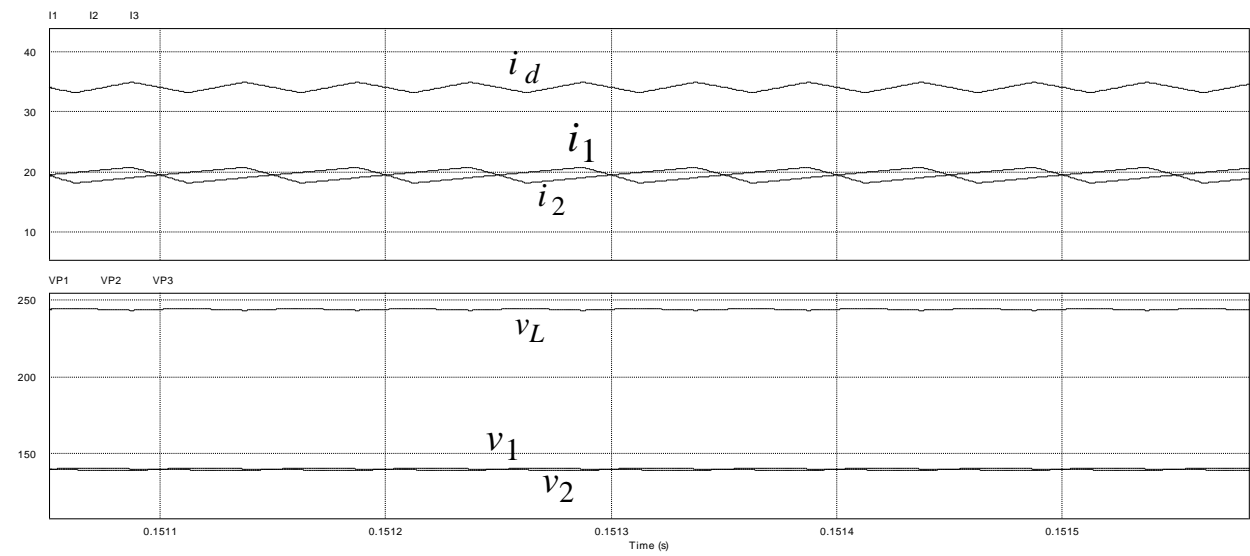

Figure 11. Simulation result of boost derived converter when duty cycle is 0.75 . 


\section{B. Simulation result for buck-boost derived power converter}

With the same data as the previous simulation, the buck-boost derived converter is simulated. Figure 12 shows the simulation result when the duty cycle is half. Once again, the result is the same as expected by the theory. Input and output ripples are very small when the duty cycle is half. Especially the output voltage ripple is almost zero under this condition. Though it is very small, the dc source current ripple of buck-boost derived converter is not zero when the duty cycle is half.

\section{Measurement result}

A high voltage-gain dc-dc power converter as shown in Figure 4 was constructed. Power MOSFET have been used as switching power devices. According to the data sheet, the ON state resistance of the power MOSFET is $0.28 \mathrm{Ohm}$. The constant voltage drop across the power diode is $0.75 \mathrm{~V}$ with negligible resistance. The two inductors have equal inductances of $4.7 \mathrm{mH}$ with resistances of $0.75 \mathrm{Ohm}$. The output filter capacitances are equal to $200 \mu \mathrm{F}$. The load is a constant resistance of $150 \mathrm{Ohm}$. The switching frequency was fixed at $5 \mathrm{kHz}$.

For this experiment, the dc input voltage is obtained by using a precision dc power supply. The dc input voltage for this dc-dc power converter was held constant at $25 \mathrm{Vdc}$.

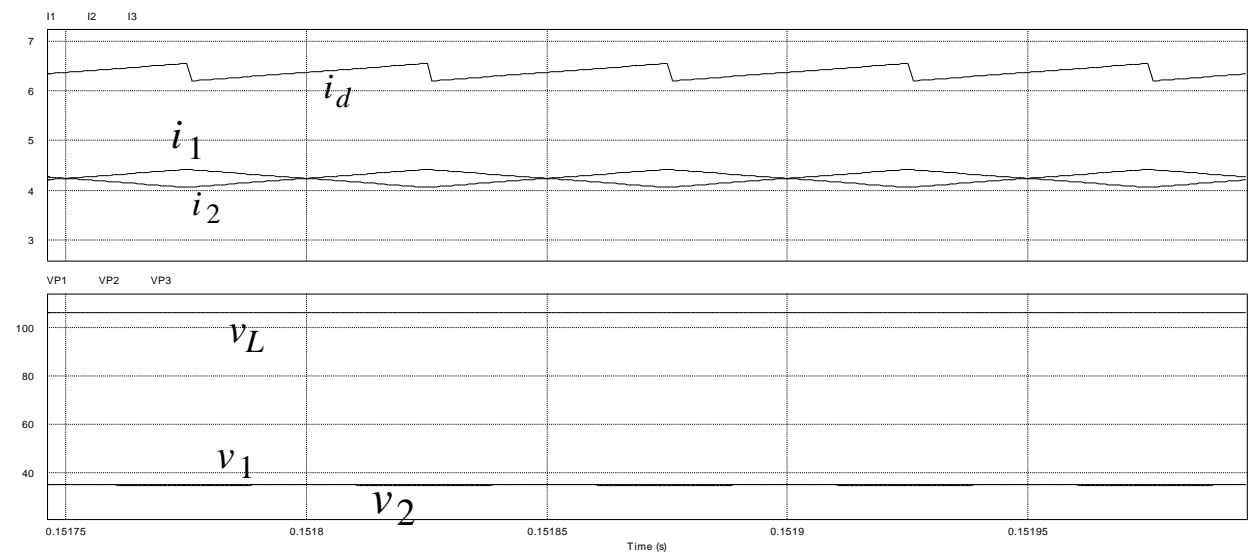

Figure 12. Simulated result of buck-boost derived converter when the duty cycle is half.

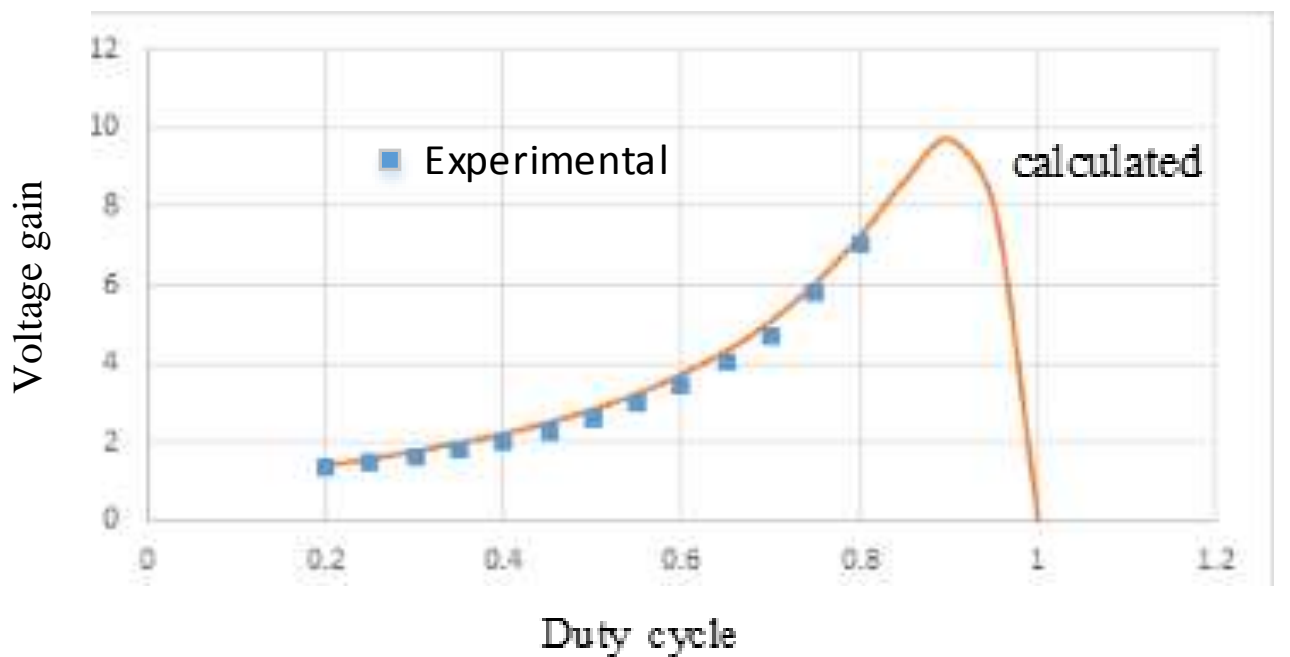

Figure 13. Comparison between measurement and calculated results of voltage-gain. 
Measurement and calculated results of voltage-gain of the proposed high voltage-gain dc-dc power converter are shown in Figure 13. In this figure, a very good agreement between measurement and calculated results can be seen. Though the components for this experimental set up have not been optimized, a voltage-gain up to more than six can be achieved easily. The voltage drop is mostly due to the voltage drop across the inductors. Further detailed loss analysis of the proposed dc-dc power converters is under investigation.

\section{Conclusion}

This paper has proposed a new method to derive high voltage-gain step-up dc-dc power converters. Four new high voltage-gain step-up dc-dc power converters have been derived. The proposed step-up dc-dc power converters have lower current and voltage ripples and also high voltage-gain capability. Compared to the original dc-dc boost power converters, the conduction losses of the derived dc-dc power converters are lower. The Cuk derived dc-dc power converter has the lowest conduction losses compared to other three dc-dc power converters. The validity of the proposed dc-dc power converter has been shown by simulation and measurement results. Control and dynamic of the proposed high voltage-gain dc-dc power converters are under investigation and will be reported in the next occasion.

\section{Acknowledgment}

The author wishes to thank LPDP, Kemenristekdikti, and PT. LEN for their supports in this research work. Assistances from my students during experimental works are gratefully acknowledged.

\section{References}

[1]. X. Yu, M. R. Starke, L. M. Tolbert, and B. Ozpineci, "Fuel cell power conditioning for electric power applications: a summary", IET Electr. Power Applications, Vol. 1, No. 5, pp. 643-656, 2007.

[2]. W. Li and X. He, "Review of nonisolated high step-up DC/DC converters in photovoltaic grid-connected applications", IEEE Trans. Ind. Electronics, Vol. 58, No. 4, pp. 1239-1250, April 2011.

[3]. F. S. Garcia, J. A. Pamilo, and G. Spiazzi, "Comparison of non-insulated, high-gain highpower, step-up DC-DC converters", IEEE Applied Power Electronics Conference, pp. 1343-1347, 2012.

[4]. F. L. Tofoli, D. C. Pereira, W. J. Paula, and D. S. O. Junior, "Survey on nonisolated highvoltage step-up dc-dc topologies based on the boost converter", IET Power Electronics, Vol. 8, No. 10, pp. 2044-2057, 2015.

[5]. D. Meneses, F. Blaabjerg, O. Garcia, and J. A. Cobos, "Review and comparison of step-up transformerless topologies for photovoltaic AC-module applications", IEEE Trans. Power Electronics, Vol. 28, No. 6, pp. 2649-2663, June 2013.

[6]. M. Forouzesh, Y. P. Siwakoti, S. A. Gorji, F. Blaabjerg, and B. Lehman, "Step-Up DC-DC converters: A comprehensive review of voltage boosting techniques, topologies, and applications", IEEE Trans. Power Electronics, Vol. 32, No. 12, pp. 9143-9178, 2017.

[7]. S. K. Changchien, T. J. Liang, J. F. Chen, and L. S. Yang, "Step-up DC-DC converter by coupled inductor and voltage-lift technique", IET Power Electronics., Vol. 3, No. 3, pp. 369-378, 2010.

[8]. W. Li, X. He, D. Xu, and B. Wu, "General derivation law of nonisolated high step-up interleaved converters with built-in transformer", IEEE Trans. Ind. Electronics, Vol. 59, No. 3, pp. 1650-1661, March 2012.

[9]. Y. T. Chen, M. H. Tsai, and R. H. Liang, "DC-DC converter with high voltage gain and reduced switch stress", IET Power Electronics, Vol. 6, No. 10, pp. 2564-2571, 2013.

[10]. A. A. Freitas, F. L. Tofoli, E. M. Junior, S. Daher, and F. L. M. Antunes, "High-voltage gain dc-dc boost converter coupled inductors for photovoltaic systems", IET Power Electronics, Vol. 8, No. 10, pp. 1885-1892, Oct. 2015. 
[11]. M. Khalizadeh and K. Abbaszadeh, "Nonisolated high step-up dc-dc converter based on coupled inductor with reduced voltage stress", IET Power Electronics, Vol. 8, No. 11, pp. 2184-2194, 2015.

[12]. R. L. Palomo and J. A. M. Saldana, "Family of quadratic step-up dc-dc converters based on noncascading structures", IET Power Electronics, Vol. 8, No.5, pp. 793-801, 2015.

[13]. A. H. Khateb, N. A. Rahim, J. Selvaraj, and B. W. Williams, "DC-to-DC converter with low input current ripple for maximum photovoltaic power extraction" IEEE Trans. Ind. Electronics, Vol. 62, pp. 2246-2256, April 2015.

[14]. S. Revathi and M. Prabhakar, "Transformerless high-gain dc-dc converter for microgrids", IET Power Electronics, Vol. 9, pp. 1170-1179, 2016.

[15]. K. C. Tseng, C. C. Huang, and C. A. Cheng, "A single switch converter with high step-up gain and low diode voltage stress suitable for green power source conversion", IEEE Emerging and Selected Topics on Power Electronics, Vol. 4, No. 2, pp. 363-372, 2016.

[16]. M. Muhammad, M. Armstrong, and M. A. Elgendy, "A nonisolated interleaved boost converter for high voltage gain applications," IEEE Emerging and Selected Topics on Power Electronics, Vol. 4, No. 2, , pp. 352-362, 2016.

[17]. P. A. Dahono, “A very large ratio dc-dc power converter", IET Conf. Renewable Power Generation, Edinburg, page 36, 2011.

[18]. F. S. Garcia, J. A. Pomilio, and G. Spiazzi, "Modeling and control design of the interleaved double dual boost converter", IEEE Trans. Ind. Electronics, Vol. 60, No. 8, pp. 3283-3290, Aug. 2013.

[19]. P. A. Dahono, "New step-up dc-dc converters for PV power generation systems", Proc. International Seminar on Intelligent Technology and Its Applications (ISITIA), 2017.

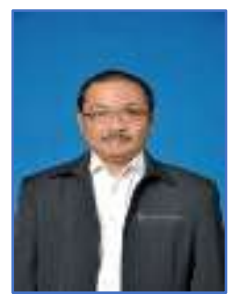

Pekik Argo Dahono, He got the Insinyur (Ir) degree, from Institut Teknologi Bandung, Indonesia, in 1985, the Master and Doctor Engineering degrees from Tokyo Institute of Technology, Japan, in 1992 and 1995, respectively, all in electrical engineering.

$\mathrm{He}$ is registered as a Professional Engineer in Indonesia and ASEAN. He is a senior member of IEEE. He is cofounder of Indonesia Smart Grid Initiatives and Indonesia Power Quality Initiatives.

At present, he is a professor in electrical engineering at the Institut Teknologi Bandung. His field of interests are power electronics and power quality. He has published more than 100 international papers. 